Original Article (short paper)

\title{
Effect of an experimental fatigue protocol applied to the quadriceps femoris muscle of physically active persons
}

\author{
Felipe Marrese Bersotti ${ }^{1,2}$ iD, Tamiris Barbosa de Melo $^{2,3}$ iD, Luis Mochizuki ${ }^{1}$ (iD, Jerônimo Rafael Skau ${ }^{2}$ iD \\ ${ }^{1}$ Universidade de São Paulo, Escola de Artes, Ciências e Humanidades, São Paulo, SP, Brasil, ${ }^{2}$ Universidade São \\ Judas Tadeu, Escola de Fisioterapia, São Paulo, SP, Brasil; ${ }^{3}$ Santa Casa de Misericórdia de São Paulo, \\ Departamento de Fisioterapia, São Paulo, SP, Brasil
}

\begin{abstract}
Aims: The purpose of this study was to test an experimental fatigue protocol for the knee joint extensor muscles performed on an isokinetic dynamometer. Method: SPIRIT recommendations were applied. Participants were 40 healthy, young men and women. Protocol: The pre-fatigue quadriceps femoris peak torque during concentric maximum voluntary contractions (MVC) at $60^{\circ} \% \mathrm{~s}$ was measured. During the first protocol part, the task was to do MVC at $60 \%$ s until a sequence of five concentric MVC was below $40 \%$ of its initial value. For the second part, intermittent quadriceps femoris muscle and hamstrings maximum voluntary isometric contractions for $30 \mathrm{~s}$ (ratio 2/1 seconds). Thirty seconds after the isometric MVC (post-fatigue), they did three concentric MVC. Then, after 5 minutes of absolute rest, they did two concentric MVC. Men and women showed a lower peak torque due to this protocol $(p<0.001)$. Conclusion: This protocol was effective for fatigue men and women's quadriceps femoris muscle.
\end{abstract}

Keywords: biomechanics; muscle fatigue; isokinetic dynamometer; knee.

\section{Introduction}

Muscle fatigue negatively influences motor function, which is the ability to perform physical tasks such as locomotion and manual tasks ${ }^{1}$. Muscle fatigue can be central and peripheral fatigue. Central fatigue changes the neural impulse reaching the muscle, and leads to voluntary impulse speed and frequency progressive reduction to the motoneurons. The peripheral fatigue changes the musculoskeletal homeostasis, and decrease the neural impulse speed ${ }^{2-4}$.

Fatigue recovery is essential for the physical capacities' development in the training and rehabilitation process, for sports practice and daily activities 5 . It is important to understand the factors that influence and are influenced by fatigue to properly avoid injuries caused by muscle fatigue ${ }^{6}$.

In the United States of America, approximately 200.000 anterior cruciate ligament (ACL) injuries occur per year ${ }^{7}$. Young athletes also suffer from declining strength and risk of knee ligament injury ${ }^{8}$. Fatigue at the recreational and competitive physical activities' end suggest changes in proprioception, affecting the neuromuscular control leading to the ligament and musculoskeletal injuries ${ }^{9}$. Muscular fatigue can impair proprioception, leading to joint damage ${ }^{10-21}$.

Fatigue protocols are different according to sex, muscular action, repetition, series, time interval, velocity and movements $^{22-25}$. The isokinetic dynamometer is a reliable instrument for training tests ${ }^{26}$ because it is possible to measure kinetics and kinematics. Regarding muscle fatigue, the fatigue peak and the initial torque varies from $6 \%$ to $50 \%{ }^{22,27}$, besides the incapability to perform the task ${ }^{2}$. Considering only the Pubmed database (July, 2019) using a specific search strategy [((()((fatigue isokinetic quadriceps) NOT injury)) NOT disease)) NOT eccentric) AND young adults], there is no published guideline about quadriceps muscle fatigue protocol for young adults without injury or disease or any consensus about repetitions or movement speed to reach quadriceps fatigue. Therefore, this study aims to test a protocol of muscular fatigue through the isokinetic dynamometer and has the hypothesis that muscular fatigue is reached after the end of the protocol. This fatigue protocol is easy to apply to men and women and it is not restricted by fitness level.

\section{Method}

Forty participants $(22.8 \pm 2.5$ years old; $73.8 \pm 14.3 \mathrm{~kg}$ mass; $169.1 \pm 11.00 \mathrm{~cm}$ ) of both sexes, healthy, without a history of lower limb injuries and instability on the knee joint participated. Inclusion criteria: to be classified as "physically active or irregularly active" according to the International Physical Activity Questionnaire IPAQ ${ }^{29}$; no lower or lower limb injuries in the last 12 months; no participation in physical or vestibular rehabilitation in the last 12 months; no hip, knee, ankle or foot joints instability; no decompensated heart failure, respiratory, vestibular or neuromuscular disorders. Exclusion criteria: inability to perform or abandon the protocol; cardiac or respiratory discomfort; and participation in heavy physical activities or sports, up to 72 hours before the test. All participants signed the Informed Consent Form. The University's ethics committee (protocol number 897.220) and Brazilian Registry of Clinical Trials (pro- 
tocol number RBR-225ksb), Universal Trial Number (U11111208-6556) approved this study. This protocol is dated December 2015 and is in its first version. All the participants were students of the University São Judas Tadeu, São Paulo, Brazil. There was no dropout.

SPIRIT recommendations were used to elaborate and determined the items for the development of experimental proto$\operatorname{cols}^{28}$. This is a cross-sectional study, which consisted of the creation and implementation of a protocol for muscle fatigue on the quadriceps femoris through an isokinetic dynamometer.

\section{Procedure}

Before the isokinetic evaluation, an anamnesis was made to each participant to investigate any possible physical compromise (confirmation of the inclusion and exclusion criteria).

An isokinetic dynamometer (Biodex System 3, Biodex Medical Systems, New York, USA) was used. It is a reliable instrument for the measurement of angular positions and velocity (Intraclass correlation coefficient ICC $=0.99)^{30}$. All the participants were placed in the isokinetic dynamometer chair and kept attached to it with bands close to the trunk, pelvis, and thigh to maintain the body stability during exertion. Positioning angles of the hip and knee were maintained at $90^{\circ}$ flexion $\left(0^{\circ}\right.$ corresponds to the complete extension of the knee joint). The segment to be tested was fixed with a velcro strap on the distal third of the leg, to maintain the stability of the movement. By positioning the participant in the isokinetic dynamometer chair, the apparent axis of the knee joint was aligned with the axis of rotation of the mechanical arm of the dynamometer. The position of the dynamometer was the same for the two parts of the study. Only the dominant lower limb was tested, which was defined as the best side to kick a ball to a 3-meters-away target.

\section{Muscular fatigue protocol}

A series of free movements with the segment of the lower limb attached to the dynamometer and a series of concentric muscular contractions with a slight resistance, manual resistance, were performed for a warm-up and familiarization with the equipment.

Muscle fatigue was caused by the isokinetic dynamometer, performed in two parts. Initially, pre-fatigue was recorded at the peak torque obtained at the beginning of concentric MVC of the femoral quadriceps at $60 \%$ s, the highest value was adopted. The protocol for muscle fatigue induction consisted of repeating concentric MVC at an angular velocity of $60 \%$, without a specific number of repetitions or series and receiving verbal stimulation all the time. The first part ends when the participant executes five concentric MVC below $40 \%$ of its initial value (peak torque). The second part, the fatigue maintenance, is a set of quadriceps femoralis muscle and hamstrings isometric MVC for $30 \mathrm{~s}$ (ratio 3/1 seconds respectively). After $30 \mathrm{~s}$ (post-fatigue) of isometric MVC, 3 concentric MVC are recorded to determine how fatigued the participant is, and after 5 minutes of absolute rest, the procedure is performed again (moment 4 ).

\section{Statistics}

The Kolmogorov-Smirnov test indicated that peak torque did not have a normal distribution. The Kruskal-Wallis test with post hoc Bonferroni was used to compare the peak torque (Nm) values in the isotonic concentric contractions of the quadriceps femoris muscle, on pre and post-fatigue conditions, after isometric and after 5 minutes rest. The software used was IBM ${ }^{\circledR}$ SPSS $®$ version 22.0. The level of significance was set at $5 \%$, with $p \leq 0.05$.

\section{Results}

Figure 1 shows the peak torque produced by men and women at the pre-fatigue, post-fatigue, pos-isometry and post-5-minutes-rest phases of the fatigue protocol.

For pre-fatigue and fatigue, the protocol was efficient. For men, the peak torque during pre-fatigue $(248.9 \pm 51.7 \mathrm{Nm})$ and fatigue $(99.5 \pm 20.6 \mathrm{Nm})$ was different $(p<0.0001$, IC 95\% 124.1 to $174.5 \mathrm{Nm})$. For women, the peak torque during prefatigue $(150.7 \pm 18.7 \mathrm{Nm})$ and fatigue $(60.3 \pm 7.5 \mathrm{Nm})$ was different ( $p<0.0001$, IC95\% 81.3 to $99.6 \mathrm{Nm}$ ).

For pre-fatigue and post-fatigue, the protocol was efficient. For men, the peak torque during pre-fatigue and postfatigue $(99.1 \pm 23.4 \mathrm{Nm})$ was different $(p<0.0001$, IC 95\% 117.9 to $181.7 \mathrm{Nm})$. For women, the peak torque during prefatigue and post-fatigue $(61.4 \pm 13.6 \mathrm{Nm})$ was different $(p<0.0001$, IC $95 \% 74.2$ to $104.4 \mathrm{Nm})$.

For post-fatigue and after five minutes rest, participants recovered from the fatigue. For men, the peak torque during post-fatigue and after 5 minutes $(196.6 \pm 34.0 \mathrm{Nm})$ was different
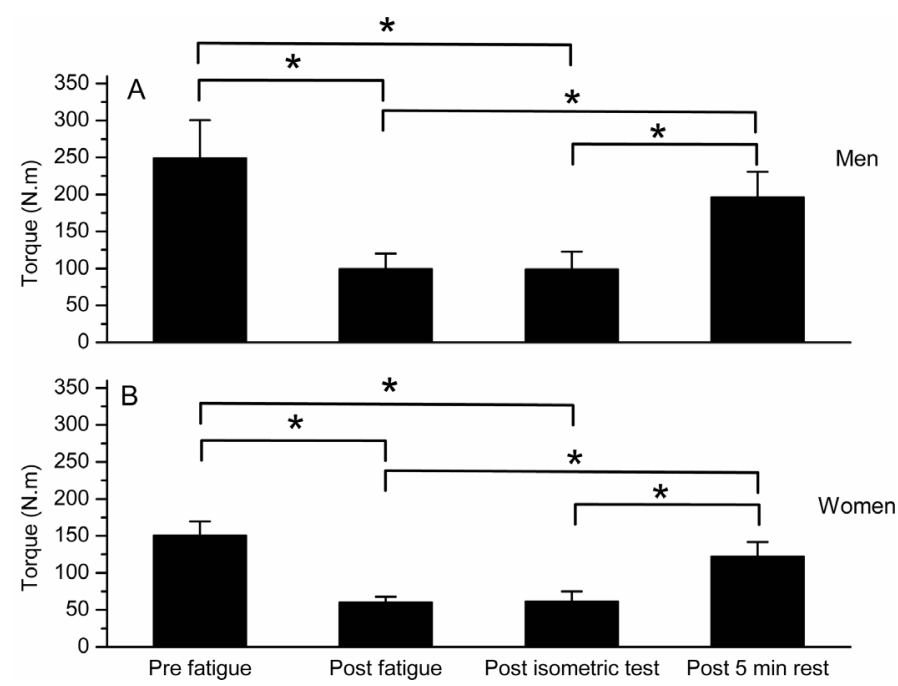

Figure 1 - A) Average and standard deviation of the men fatigue values: pre-fatigue, post-fatigue, pos-isometry and post 5 minutes rest. B) Average and standard deviation of the women fatigue values: pre-fatigue, post-fatigue, post-isometry and post 5 minutes rest. ${ }^{*} p \leq 0.05$ between stages. 
$(p<0.0001$, IC 95\% -74.8 to -28.4). For women, the peak torque during post-fatigue and after 5 minutes $(122.11 \pm 19.38 \mathrm{Nm})$ was different ( $p<0.0001$, IC 95\% -73.8 to -47.5).

For all comparisons, effect size $>0.8$ and a power effect was 1.0 .

\section{Discussion}

This study applied the isokinetic dynamometry to successfully induce the quadriceps femoris muscle fatigue. In addition, active recovery at the first 30 seconds (two sets of extensor muscles isometric contraction (10 s) and flexor muscles isometric contraction (5 s)) after fatigue was enough to sustain the quadriceps femoris muscle fatigued. Our fatigue protocol maintained the quadriceps femoris muscle fatigue (60\% drop) at $60^{\circ} / \mathrm{s}^{22,27,31,32}$, and with intermittent isometric contractions ${ }^{24}$. Our study considered the decline in muscle strength and not how many knee joint flexion and extension repetitions each individual had to perform to achieve the $60 \%$ drop in maximum concentric peak torque. Men had a higher torque than women. Other studies applied similar fatigue protocols in $\mathrm{men}^{31,33}$, but not in women.

Drop-in peak torque is fatigue information. We used the peak torque to determine muscle fatigue. Other studies have also accounted for time. Tiggelen, Coorevits, Witvrouw ${ }^{40}$ asked men and women to continuously flex and extend their knees for $150 \mathrm{~s}$ without any break at $120 \%$ s, and they found the reduction of peak torque. Carregalo, Gentil, Brown, Pinto, Bottaro ${ }^{22}$ applied three different fatigue protocols comparing the peak torque. The first protocol was three sets of ten contractions in the concentricconcentric mode (a concentric contraction of the knee joint extensor muscles and knee joint flexors) with one-minute break between sets. The second protocol was sets of 10 maximal stretches of concentric contraction, with one-minute break between sets. The third protocol was 20 maximum concentric flexions and extensions movements. They found fatigue when participants did the exercises at $60 \%$ s and $180^{\circ} / \mathrm{s}$.

Different protocols for muscle fatigue are used according to the literature. Different instruments (ergometric bicycle ${ }^{34}$, weight lifting ${ }^{35}$ and the isokinetic dynamometer) can induce muscle fatigue. Fatigue protocols were applied in persons with different levels of physical activity ${ }^{32,33,39,40}$. For example, in Derave, Ozdemir, Harris, Pottier, Reyngoudt, Koppo, Wise, Achten $^{39}$, male athletes had lower fatigue than non-athletes. It is easy and reliable to control muscular strength, torque, angular velocity, type of muscle contraction with the isokinetic dynamometer $^{22,23,36,37}$. In a systematic review, Suzuki, Mazuchi, Miranda, Maifrino, Mochizuki, Ervilha ${ }^{6}$ showed the greatest reduction in maximum torque occurs in protocols that use sets of exercises with no fixed repetitions number, requiring performance until exhaustion.

The movement velocity is an important factor to induce fatigue. In our study, $60 \%$ seconds was enough for quadriceps femoris muscle fatigue. However, we did not account for how many repetitions did each participant to reach fatigue. In a pilot study, we observed that lower angular velocities induce muscle fatigue faster than the highest angular velocities. Other studies have a fixed number of repetitions to induce fatigue. Astorino, Terzi, Roberson, Burnett' s protocol ${ }^{23}$ was two sets of 40 maximal knee extensions with three minutes break between sets at $180 \%$ s. Carregalo, Gentil, Brown, Pinto, Bottaro ${ }^{22}$ showed lower maximum peak torque at $60 \%$ s.

Thirty seconds break was enough between sets. Comparing 15, 30 and $60 \mathrm{~s}$ breaks, young and physically active older women showed lower knee extensor torque when the break dropped from $30 \mathrm{~s}$ to $15 \mathrm{~s}$; but similar torques comparing 30 and $60 \mathrm{~s}^{39}$. In addition, from our pilot study, only a five seconds break is not enough to promote the recovery of strength and thus maintains the state of muscle fatigue.

\section{Conclusion}

We conclude that the muscle fatigue protocol applied in the present study was effective in leading to quadriceps femoris muscle fatigue. After muscle fatigue, the intermittent isometric contractions of quadriceps femoris muscle with a rest interval of five seconds keep it fatigued, a fact that was verified by the reduction of $50 \%$ of the peak torque after one-minute of fatigue when compared with pre-fatigue condition.

We did not investigate the effects of this fatigue protocol on tasks that require motor control, internal force studies or kinematic analysis. The protocol of fatigue demonstrated that other studies are needed to verify if the quadriceps muscle fatigue significantly affects the control of the knee joint.

\section{References}

1. Enoka RM. Stuart DG. Neurobiology of muscle fatigue. J Appl Physiol. 1992; 72: 1631-1648.

2. Enoka RM, Duchateau J. Translating Fatigue To Human Performance. Med Sci Sports Exerc. 2016; 48 (11): 2228-2238. Doi: 10.1249/Mss.0000000000000929.

3. Davies M, Bailey S. Possible Mechanisms of Central Nervous System Fatigue During Exercise. Med Sci Sports Exercise. 1997; 29(1):45-57.

4. Gandevia SC, Enoka RM, Mccomas AJ, Stuart DG, Thomas CK. Neurobiology Of Muscle Fatigue. Advances And Issues. Adv Exp Med Biol. 1995; 4(38): 515-525.

5. Gioftsidou AF, Malliou P, Pafis G, Beneka A, Tsapralis K, Sofokleous P, Kouli O, Rokka SE, George G. Balance Training Programs For Soccer Injuries Prevention. JHSE. 2012; 7(3): S69-S74.

6. Suzuki FS, Mazuchi FAS, Miranda MLJ, Maifrino LBM, Mochizuki L, Ervilha UF. What Is The Most Effective Protocol To Induce Fatigue In Knee Joint Muscles? A Systematic Review. Braz. j. morphol. sci. 2013; 30:143-147.

7. Wetters N, Weber Ae, Wuerz Th, Schub Dl, Mandelbaum Br. Mechanism Of Injury And Risk Factors For Anterior Cruciate Ligament Injury. Oper Tech Sports Med. 2016; 24(1): 2-6.

8. Rumpf Mc. Cronin J. Injury Incidence, Body Site, And Severity In Soccer Players Aged 6-18 Years: Implications For Injury Prevention. Strength Condit J. 2012; 34 (1): 20-31. 
9. Lehnert M, Croix MS, Xaverova Z, Botek M, Varekova R, Zaatar A, Lastovicka O, Stastny P. Changes In Injury Risk Mechanisms After Soccer-Specific Fatigue In Male Youth Soccer Players. J Hum Kinet. 2018;62: 33-42. Doi: 10.1515/Hukin-2017-0157

10. Hiemstra LA, Lo IK, Fowler PJ. Effect Of Fatigue On Knee Proprioception: Implications For Dynamic Stabilization. J Orthop Sports Phys Ther. 2001; 31(10):598-605.

11. Skinner HB, Wyatt MP, Hodgdon JA, Conard DW, Barrack R1. Effect Of Fatigue On Joint Position Sense Of The Knee. J Orthop Res. 1986; 4:112-118.

12. Blasier RB, James EC, Laura JH. Shoulder Proprioception: Effect Of Joint Laxity, Joint Position, Direction Of Motion, And Muscle Fatigue. Orthop Rev. 1993; 23:45-50.

13. Voight ML, Harden JA, Blackburn TA, Tippet S, Canner GC The Effect Of Muscle Fatigue On The Relationship Of Arm Dominace To Shoulder Proprioception. J Orthop Sports Phys Ther. 1996; 23(6):348-352.

14. Lattanzio PJ, Petrella RJ, Sproule JR, Fowler PJ. Effects Of Fatigue On Knee Proprioception. Clin J Sport Med. 1997; 7:22-27.

15. Carpenter JE, Blasier RB, Pellizzon GG. The Effects Of Muscle Fatigue On Shoulder Joint Position Sense. Am J Sports Med. 1998;26(2):262-265

16. Pedersen J, Lonn J, Hellstrom F, Djupsjoback M, Johansson H. Localized Muscle Fatigue Decreases The Acuity Of Movement Sense In The Human Shoulder. Med Sci Sports Exerc. 1999;31(7):1047-1052.

17. Taimela S, Kankaanpaa M, Luoto S. The Effect Of Lumbar Fatigue On The Ability To Sense A Change In Lumbar Position. A Controlled Study. Spine. 1999;24:1322-1327.

18. Bjorklund M, Crenshaw AG, Djupsjobacka M, Johansson H. Position Sense Acuity Is Diminished Following Repetitive LowIntensity Work To Fatigue In A Simulated Occupational Setting. Eur J Appl Physiol. 2000;81:361-367.

19. Forestier N, Teasdale N, Nougier V. Alteration Of The Position Sense At The Ankle Induced By Muscular Fatigue In Humans. Med Sci Sports Exerc. 2002; 34 (1):117-122.

20. Lee HM, Liau JJ, Cheng CK, Tan CM, Shih JT. Evaluation Of Shoulder Proprioception Following Muscle Fatigue. Clin Biomech. 2003;18:843-847

21. Tripp BL, Boswell L, Gansneder BM, Shultz SJ. Functional Fatigue Decreases 3-Dimensional Multijoint Position Reproduction Acuity In The Overhead-Throwing Athete. J Athl Train. 2004;39(4):316-320.

22. Carregalo RL, Gentil P, Brown LE, Pinto RS, Bottaro M. Effects Of Antagonist Pre-Load On Knee Extender Isokinetic Muscle Performance. J. Sports Sci. 2011;29: 271-278.

23. Astorino Ta, Terzi Mn, Roberson Dw, Burnett Tr. Effect Of Two Doses Of Caffeine On Muscular Function During Isokinetic Exercise. Med Sci Sports Exerc. 2010;42: 2205-2210.

24. Rawson Es. Enhanced Fatigue Resistance In Older Adults During Repeated Intermittent Contractions. J. Strength Cond. Res. 2010;24(1):251-256

25. Dipla K, Tsirini T, Zafeiridis A, Manou V, Dalamitros A, Kellis E, Kellis S. Fatigue resistance during high-intensity intermittent exercise from childhood to adulthood in males and females. Eur J Appl Physiol. 2009;106(5):645-653. doi: 10.1007/s00421-009-1058-x

26. Ordway NR, Hand N, Briggs G, Ploutz-Snyder LL. Reliability of knee and ankle strength measures in an older adult population. J Strength Cond Res. 2006 Feb;20(1):82-87.

27. Kellis E. Antagonist Moment Of Force During Maximal Knee Extension In Pubertal Boys: Effects Of Quadriceps Fatigue. Eur J
Appl Physiol. 2003;89:3-4.

http://dx.doi.org/10.1007/s00421-003-0795-5

$271-280$

28. Chan AW, Tetzlaff JM, Altman DG, Laupacis A, Gøtzsche PC, Krleza-Jeric K, et al. SPIRIT 2013 Statement: Defining standard protocol items for clinical trials. Ann Intern Med. 2013;158:200-207.

29. Guedes DP, Lopes CC, Guedes JERP. Reprodutibilidade e validade do Questionário Internacional de Atividade Física em adolescentes. Rev Bras Med Esporte. 2005, 11:2 Doi: 10.1590/S1517-86922005000200011

30. Drouin JM, Valovich-mcLeod TC, Shultz SJ, Gansneder BM, Perrin DH. Reliability and validity of the Biodex system 3 pro isokinetic dynamometer velocity, torque and position measurements. Eur J Appl Physiol. 2004 ;91(1):22-29.

31. Mercer TH, Gleeson NP, Wren K. Influence Of Prolonged Intermittent High-Intensity Exercise On Knee Flexor Strength In Male And Female Soccer Players. European Journal applied Physiology. 2003; $\quad$ 89(5): doi:10.1007/s00421-003-0830-6

32. Molinari F, Knaflitz M, Bonato P, Actis MV. Electrical Manifestation Of Muscle Fatigue During Concentric And Eccentric Isokinect Knee Flexion-extension Movements. IEEE Transactions Biomedical Engineering. 2006; 53: 1309-1316. Doi:10.1109/TBME.2006.873680

33. Gabriel D, Proctor D, Engle D, Nair S, Vittone J, An KN. Applicaion Of The LaGrange Polynomial In Skeletal Muscle Fatigue Analysis. Res Q Exercise Sport. 2002;73(2):168-174. Doi:10.1080/02701367.2002.10609005

34. Kraemer Wj, Gardiner Df, Gordon Se, Koziris Lp, Sebastianelli W, Putukian M, et al. Differential effects of exhaustive cycle ergometry on concentric and eccentric torque production. J Sci Med Sport.2001; 4(3): 301-309.

35. Raastad T, Risoy Ba, Benestad Hb, Fjeld Jg, Hallén J. Temporal relation between leukocyte accumulation in muscle and halted recovery 10-20 after strength exercise. J Appl Physiol. 2003; 93:2503-2509.

36. Arroyo-Morales M, Fernandez-Lao C, Arizagarcia A, Toro-Velasco C, Winters M, Diasrodrigues L, Cantarero-Villanueva I, Hujibregts P, Fernandez-De-Las-Peñas C. Psychophysiological Effects Of Preperformance Massage Before Isokinetic Exercise. J. Strength Cond. Res. 2011;25:481-8.

37. Blacker Sd, Fallowfield Jl, Bilzon Jlj,Willens Met. Neuromuscular Function Following Prolonged Load Carriage On Level An Downhill Gradients. Aviat Space Environ Med. 2010; 81(8):745-753.

38. Theou O, Gareth J.R, Brown LE. Effects of rest intervalo $n$ strength recovery in Young and old women. J. Strength Cond. Res. 2008; 22(6):876-881.

39. Derave W, Ozdemir Ms, Harris Rc, Pottier A, Reyngoudt H, Koppo K, Wise Já, Achten E. Beta-Alamine supplementation augments muscle carnosine content and attenuates fatigue during repeated isokinetic contraction bouts in trained springers. J Appl Physiol. 2007;103:1736-1743.

40. Tiggelen DV, Coorevits P, Witvrouw E. The effects of a neoprene knee sleeve on subjects with a poor versus good joint position sense subjected to an isokinetic fatigue protocol. Clin J Sport Med. 2008;18(3):259-264.

\section{Acknowledgments}

Support to Fundação de Amparo à Pesquisa do Estado de São Paulo - FAPESP n²018/23429-6. 
Corresponding author

Felipe Marrese Bersotti

Escola de Artes, Ciências e Humanidades.

Universidade de São Paulo.

São Paulo, SP, Brazil.

E-mail: felipemarresebersotti@hotmail.com

Manuscript received on May 19, 2019
Manuscript accepted on August 28, 2019

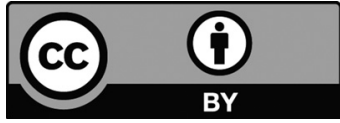

Motriz. The Journal of Physical Education. UNESP. Rio Claro, SP, Brazil eISSN: 1980-6574 - under a license Creative Commons - Version 4.0 